\title{
Acceptance of an Online Voting System at the Catholic University Institute of Buea
}

\author{
Damen Nyinkeu Ngatchu, Catholic University Institute of Buea, Cameroon \\ Andrew M. Ngwa, ICT University, Yaounde, Cameroon \\ Susannash Limunga Esowe, ICT University, Yaounde, Cameroon
}

\begin{abstract}
Increasingly, more software is developed locally, to address the needs of the developer's immediate community and yet little research has been done regarding their acceptance. The technology acceptance model (TAM), which has greatly been used in literature, failed to consider some cultural particularities of such software. Furthermore, most research has focused on the acceptance of foreign technologies in Africa. The primary objective of this article, is to investigate the validity of TAM for locally developed software within a community. The article utilizes quantitative methodology based on data gathered using a modified version of a published survey instrument; as well as Short Message Service for the collection of qualitative data. The findings concur with previous studies on technology acceptance and the raises interests on the use of qualitative data for understanding the context of technology acceptance.
\end{abstract}

\section{KEYWORDS}

Multiple Methods, Online Voting Systems (OSV), Short Message Service (SMS), Software Development, SubSaharan Africa (SSA), Technology Acceptance Model (TAM)

\section{INTRODUCTION}

The upsurge of technology in Africa in the last few years has touched almost every sector of every industry from education, through business to agriculture. A wide variety of technologies have been applied to these industries including computers, electronic learning environments, mobile phones and technology-driven service-provider platforms. Research efforts on acceptance and adoption of these technologies in and around Africa (Averweg, 2008; Afari, 2010; Lwasa et al., 2011; Okuboyejo and Adejo, 2012) is currently on the rise and the findings have significantly contributed to the body of knowledge regarding technology acceptance and adoption. However, most studies have examined the acceptance and adoption of technology that is developed out of Africa.

The processes and procedures for development of computer software have experienced considerable metamorphosis in the last two decades. Rico (2010) presents a short history of software development in relation to market conditions and shows how the transition forms waterfall software development methodology to current Agile methodology is related to the desire to create flexible software. The integration of Toyota's Lean manufacturing principles and practices into the software 
development domain (Poppendieck and Poppendieck, 2003; Ladas 2008) has led to an "on-the-fly" consumption of software, while it is being developed. It is intriguing, therefore, to investigate user's acceptance of such software. The objective of this study is to explore the role of context in the technology acceptance process, while verifying and validating the fit of the renowned technology acceptance model to the context.

In 2014, the students and faculty of the School of Information Technology at the Catholic University Institute of Buea developed an Online Voting System (OVS) which was used for the elections of the president for the Student Government Association (STUGA). The web-based platform enabled students to register for the elections, view posters of the various presidential hopefuls and at the appointed voting period, make a selection of their desired candidate. Considering the shift in technology development methodology, particularly software development, it becomes difficult to dissociate the development process from the adoption process; given that in some cases, the developers and users live in the same community.

The development of the OVS followed the Lean methodology and provides a fertile ground for investigating the afore mentioned gaps in scientific literature regarding technology acceptance and adoption. The scene for this study has therefore been set partially by experiences in training software engineers in Africa but mainly by need to explore and understand the technology acceptance process from a contextual stand point. The findings reveal that users paid very little attention to the development process and focused on their use-experience. Quantitatively, they concur with previous studies on technology acceptance yet raise interests on the use of qualitative data for understanding the context of technology acceptance.

\section{LITERATURE REVIEW}

Since its introduction in 1989 by Fred Davis, the Technology Acceptance Model (TAM) has gone through validation, extension and elaboration, benefiting from the works of renown authors and partially defining the academic discipline of information and communication technology. The model proffers that the perceived ease-of-use and the perceived usefulness of a technology are the principal constructs that determine user behavioral intension and actual use towards a particular technology. An earlier systematic review (Lee et al., 2003) of articles relating to TAM highlighted the stages of the model's metamorphosis (Introduction, Validation, Extension and Elaboration) and expressed the need "...to develop the next generation TAM that synthesizes the previous effects and to resolve the limitations raised by previous studies." (Lee et al., 2003, p. 757).

In the last decade, scholarly literature has witnessed the application of TAM to a wide variety of technological artifacts. Within the education industry, Eben and Akwasi (2010), Arumugam (2011) and Kung-Teck et al (2013) have studied the acceptance and adoption of computers by students in Ghana and Malaysia. Kumar-Sharma et al (2014) and Amer et al. (2013) studied the acceptance of e-learning platforms amongst University Students in Oman and in Yemen. The result of this effort is the appearance of enhanced and new models for studying technology-users' behavior.

A prominent enhanced version of the technology acceptance model, rightly called TAM2, has been used (Jaradat and Faqih, 2014; Omotayo and Dahunsi, 2015; Güllü, et al., 2016) to elaborate and investigate the influence of different constructs (Output Quality; Result Demonstrability; Facilitating conditions; Performance enhancement) to the original TAM. The Unified Theory of Acceptance and Use of Technology (UTAUT) has equally gained popularity in the discipline. Tan (2013) applied UTAUT to understand the factors affecting the use of English e-Learning websites; Antwi et al., (2014) analyzed the adoption and use of medical ICTs based on UTAUT while Boakye (2015) used it to explore the determinants of student utilization of computer information retrieval systems in academic libraries.

In all the above publications, none of them insinuated any linkage between the technology under investigation, its development process and their relationship with the user community. This missing 
link in literature encapsulates the concerns raised in Lee et al (2003) - the need to focus on measuring the actual usage of technology over the self-reported usage and to relate TAM to performance improvement. The emphasis on contextual factors when investigating technology adoption had earlier been noted by researchers (Meso and Mbarika, 2005; Averweg, 2008) and despite the drift towards enhanced and new models, such emphasis seems to have been side-lined.

\section{THEORETICAL FRAMEWORK}

A return to Davis' (1989) model as the theoretical framework for this study is based partly on the traditional tendency to build upon the works of previous researchers; but more importantly, on the inclination to verify and confirm Davis' postulations while exploring the context of technology acceptance. TAM is an adaptation from the Theory of Reasoned Action (TRA), which aims to address users' acceptance of information systems. It posits that Perceived Usefulness (PU) and Perceived Ease of Use (PEOU) are two primary beliefs that determine attitude towards a behavior (Davis et al 1989) and mediate the effects of external variables such as system design characteristics, job relevance and social influence.

PU is defined as the extent to which a person believes that using an information system will enhance his or her job performance and PEOU is defined as the degree to which a person believes that using an information system will be free of effort (Davis et al., 1989). As seen in Figure 1, the Attitude towards Using (ATU), which is defined as the degree to which an individual evaluates and associates the target system with his or her job (Shroff, et al., 2011) is related to users' behavioral intension (BI). A major limitation of TAM research has been with the measurement of the actual use (AU) construct. As a measure of AU, some studies have resorted to a measure of participants' intension to use an information system (Afari, 2010; Amer et al., 2013) while others (Averweg, 2008; Arumugam, 2011) have measured self-reported use of the IS. In either case, TAM consistently explains about $40 \%$ of the variance in individuals' intention to use information technology and actual usage (Venkatesh and Bala, 2008).

Critiques of TAM would advocate for different theoretical framework, for this study, on the basis that TAM is old and seemingly over researched. However, little research has been done from a contextual perspective, Among the 101 articles surveyed in Lee et al., (2003) only three of them used qualitative data of participatory observations and content analysis. A more recent reviews of (Rana et al., 2013; Ahlan and Ahmad, 2015) show that researcher continue to focus on the initial constructs of TAM and using quantitative methods for measuring these constructs. In their implication for future research, Yucel and Gulbahar (2013) expressed the need for research to focus on "...what makes technology useful and easy to use?" Such questions are certainly contextual and re-echo the voices of other (Musa et al, 2005; Srite and Karahanna, 2006; Averweg, 2008), had earlier called for a re-examination of TAM within specific contexts, particularly the Sub-Saharan context. In the last decade, the proliferation of technology use in Sub-Saharan Africa, especially amongst the younger generation warrants scholars to look again into what makes people accept and adopt technology.

Figure 1. Technology Acceptance Model (TAM) (Davis et al., 1989)

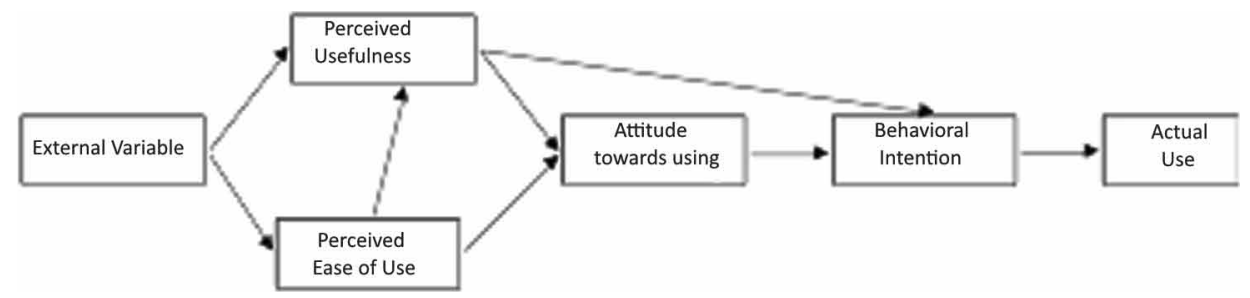


In response to this call, and in line with the objectives of this study, the contextual setting for the acceptance of the online voting system is explored qualitatively while the the following five hypotheses (see Figure 1) are quantitatively tested:

H1: Perceived Usefulness (PU) of the OVS will have a significant influence on users' attitude towards usage (ATU) of the system.

H2: Perceived Ease of Use (PEOU) of the OVS will have a significant influence on attitude towards usage (ATU) of the system.

H3: Perceived Ease of Use (PEOU) of the OVS will have a significant influence on users' perceived usefulness (PU) of the system.

H4: Users' Attitude Towards Usage (ATU) of the OVS will have a significant influence on their behavioral intention (BI) to use the system.

H5: Perceived Usefulness (PU) of the OVS will have a significant influence on users' behavioral intention (BI) to use the system.

\section{RESEARCH METHODOLOGY}

In recent years, the differences in approach to scientific investigation by qualitative and quantitative research are seen as complimentary by supporters of mixed methods research (MMR). MMR can be defined as a research approach that combines and integrates quantitative and qualitative research approaches (Gelo et al, 2008). Philosophically, MMR is founded on thinking dialectically; using a new paradigm; being pragmatic and putting substantive understanding (Greene and Caracelli, 2003, as cited by Gelo et al, 2008) into the nature of reality. It considers an interactive continuum between qualitative and quantitative methodologies and offers an array of research designs from which researchers can choose based on the purpose of the investigation.

The acceptance and adoption of technology arises out of actions, situations, and consequences rather than antecedent conditions or a small discrete set of ideas. In any situation, the action of an individual or a group of persons has particular consequences on the individual, the group and other. In the case of the Online Voting System (OVS), the University's administration made an executive decision for the system to be used. This decision was facilitated by a presentation of the system's prototype from the students and faculty of the School of Information Technology. In the end, the entire University community used the OVS for the elections of the Student Government President. Such pragmatism mandates that investigation into how the OVS was accepted at CUIB follows a mixture of methods and aligns with the objectives of the study.

\section{Research Design}

A variant of the triangulation approach to scientific investigation (Creswell et al. 2003; Creswell and Plano Clark 2007) is employed. The multilevel model (Tashakkori and Teddlie 1998) which utilizes different methods (quantitative and qualitative) to address different levels within research. The goal here is to collect different but complementary data to expand quantitative results with qualitative data. In tandem with other researchers (Elliott and Williams, 2002), we choose to use quantitative data for the University-wide level and qualitative data at the level of developers, administration, student government, and different categories of the OVS users. This cross-sectional design approach guarantees a better understanding of the acceptance of the OVS at its infancy as well as the relationship between the acceptance and the development process.

\section{Research Method}

A survey instrument was developed based on previous instruments used in published papers (Davis, 1989; Davis et al., 1989; Averweg, 2008). The research model is a simple TAM model with the 
well-researched constructs of PU, PEOU, BI and AU (Davis et al., 1989; Averweg, 2008; Shroff et al, 2011, Ambak et al, 2013). A pilot test of the instrument was conducted and feedback from the test was incorporated into the newer version of the instrument. The Five schools of the University were used as the strata for a systematic stratified sampling technique to sample faculty, staff and students. This is to guard against the error of an unrepresentative sample especially with differences in technological inclinations of the various schools.

Descriptive analyses of the data were carried out to determine the characteristics of the sample. Using SPSS, we conducted reliability analysis, internal consistency checks, correlation and regression analysis.

\section{FINDINGS AND DISCUSSIONS}

The findings from the analysis of the quantitative data are presented in the subsections below. First, data was gathered using the survey instrument; then the construct validity of the items of the instrument was tested. Next the discriminant validity was assessed by inspecting the correlations between the four factors (PU, PEOU, ATU and BI) and the hypotheses were tested.

On the other hand, the findings from the analysis of qualitative data, gathered through focused group discussions, have been presented within the discussions and analysis section in a bid to deepen and contextualize our understanding of the acceptance of the OVS.

\section{Descriptive Statistics}

A total of One Hundred and One (101) questionnaires were distributed and a response rate of eightythree percent (83\%) was recorded. Sixty-three percent (63\%) of the respondents where male which is reflective of the gender distribution of the University and twenty percent (20\%) of the respondents were Freshmen. Although the system was used for the election of the Student Government President, fifteen percent $(15 \%)$ of the respondents where staff, administrators and faculty members.

The descriptive statistics of four variables are presented in Table 1. All the means are above the midpoint of 3.00 and the standard deviations range from 1.67 to 2.06; indicating a narrow spread of values around the mean.

\section{Construct Validity}

The constructs of the study were adopted from the work of Shroff et al. (2011), whose instrument served as the basis for the instrument used in this study. The reliability of the constructs have been analyzed using Cronbach's alpha (Cronbach, 1951, 1970). All the measures employed in this study demonstrated excellent internal consistency, ranging from 0.79 to 0.89 (see Table 1), thereby exceeding the reliability estimates $(\alpha=0.70)$ recommended by Nunnally (1967).

\section{Discriminant Validity}

In line with the works of Bagozzi \& Phillips (1991), the discriminant validity was assessed by inspecting the correlation between the four constructs. The means of the various items in the instrument that measured the constructs have been used for the computation of the correlations in Table 2 .

The two-tailed test of significance reveal that all correlations are significant at the 0.001 level. The results show strong correlation between the constructs and thus a reasonable discriminant and convergent validity of the measures.

\section{Hypotheses Testing}

In order to test the hypotheses of the theoretical framework of this study, a series of linear regression analyses was carried. Table 3 tabulates, for each of the hypotheses, the dependent variable (DV), the independent variable (IV) and the outputs of the regression analyses. Creswell's (2012) recommendation for statistical significance (probability value $<0.05$ ) in social science research was adopted. 
Table 1. Summary of means and standard deviations

\begin{tabular}{|c|c|c|c|c|}
\hline Factors & Survey Questions & Means & $\begin{array}{l}\text { Standard } \\
\text { Deviation }\end{array}$ & Cronbach's Alpha \\
\hline \multirow{5}{*}{ Perceived Usefulness (PU) } & 7 & 4.98 & 1.99 & \multirow{5}{*}{0.79} \\
\hline & 12 & 5.36 & 1.78 & \\
\hline & 16 & 5.12 & 1.77 & \\
\hline & 18 & 5.04 & 1.72 & \\
\hline & 23 & 4.34 & 1.97 & \\
\hline \multirow{5}{*}{$\begin{array}{l}\text { Perceived Ease of Use } \\
\text { (PEOU) }\end{array}$} & 10 & 5.40 & 1.68 & \multirow{5}{*}{0.87} \\
\hline & 14 & 5.24 & 1.69 & \\
\hline & 17 & 4.98 & 1.83 & \\
\hline & 19 & 4.87 & 1.78 & \\
\hline & 25 & 5.20 & 1.73 & \\
\hline \multirow{5}{*}{$\begin{array}{l}\text { Attitude Towards Use } \\
\text { (ATU) }\end{array}$} & 11 & 5.28 & 1.67 & \multirow{5}{*}{0.86} \\
\hline & 15 & 5.39 & 1.72 & \\
\hline & 20 & 4.16 & 1.72 & \\
\hline & 21 & 4.81 & 1.85 & \\
\hline & 24 & 4.73 & 1.69 & \\
\hline \multirow{4}{*}{ Behavioral Intend (BI) } & 8 & 4.92 & 1.93 & \multirow{4}{*}{0.89} \\
\hline & 9 & 4.88 & 2.06 & \\
\hline & 13 & 5.17 & 1.70 & \\
\hline & 22 & 4.83 & 1.79 & \\
\hline
\end{tabular}

Table 2. Inter-correlation between constructs

\begin{tabular}{|l|l|l|l|l|}
\hline \multicolumn{1}{|c|}{ Construct } & \multicolumn{1}{c|}{ PU } & \multicolumn{1}{c|}{ PEOU } & \multicolumn{1}{c|}{ ATU } & BI \\
\hline Perceived Usefulness (PU) & 1 & & & \\
\hline Perceived Ease of Use (PEOU) & 0.760 & 1 & & \\
\hline Attitude Towards Use (ATU) & 0.801 & 0.709 & 1 & \\
\hline Behavioral Intend (BI) & 0.687 & 0.571 & 0.829 & 1 \\
\hline
\end{tabular}

The results show that all five hypotheses were supported. Perceived usefulness (PU) of the OVS has a significant influence on users' attitude towards usage (ATU) of the system $(\beta=0.801, \mathrm{p}<0.05)$. Hypothesis (H1) is supported and PU has a significant and positive impact on ATU. Perceived ease of use (PEOU) of the online voting system has a significant influence on users' attitude towards usage (ATU) of the system $(\beta=0.709, \mathrm{p}<0.05)$. Hypothesis $(\mathrm{H} 2)$ is supported and PEOU has a significant and positive impact on ATU. Perceived ease of use (PEOU) of the online voting system has a significant influence on users' perception of the usefulness (PU) of the system $(\beta=0.760, \mathrm{p}<$ 0.05). Hypothesis (H3) is supported and PEOU has a significant and positive impact on PU. Users' attitude towards the usage (ATU) of the online voting system has a significant influence on their behavioral intention (BI) to use the system $(\beta=0.829, \mathrm{p}<0.05)$. Hypothesis (H4) is supported and ATU has a significant and positive impact on BI. Perceived usefulness (PU) of the online voting 


\begin{tabular}{|c|c|c|c|c|c|c|c|c|}
\hline \multirow{2}{*}{ Hypotheses } & \multirow{2}{*}{ D V } & \multirow{2}{*}{ I V } & \multicolumn{2}{|c|}{ Unstandardized } & \multirow{2}{*}{ Std. B } & \multirow{2}{*}{$\mathbf{t}$} & \multirow{2}{*}{ Sig. } & \multirow{2}{*}{ Adjusted R sq } \\
\hline & & & B & Std. Error & & & & \\
\hline \multirow{2}{*}{$\mathrm{H} 1$} & \multirow{2}{*}{ ATU } & CONST & 0.925 & 0.336 & & 2.749 & 0.007 & \multirow{2}{*}{0.637} \\
\hline & & PU & 0.792 & 0.065 & 0.801 & 12.122 & 0.000 & \\
\hline \multirow{2}{*}{$\mathrm{H} 2$} & \multirow{2}{*}{ ATU } & CONST & 1.481 & 0.386 & & 3.841 & 0.000 & \multirow{2}{*}{0.496} \\
\hline & & PEOU & 0.663 & 0.073 & 0.709 & 9.099 & 0.000 & \\
\hline \multirow{2}{*}{$\mathrm{H} 3$} & \multirow{2}{*}{ PU } & CONST & 1.301 & 0.359 & & 3.620 & 0.001 & \multirow{2}{*}{0.572} \\
\hline & & PEOU & 0.719 & 0.068 & 0.760 & 10.584 & 0.000 & \\
\hline \multirow{2}{*}{$\mathrm{H} 4$} & \multirow{2}{*}{ BI } & CONST & 0.275 & 0.361 & & 0.762 & 0.448 & \multirow{2}{*}{0.684} \\
\hline & & ATU & 0.961 & 0.072 & 0.829 & 13.439 & 0.000 & \\
\hline \multirow{2}{*}{ H5 } & \multirow{2}{*}{ BI } & CONST & 1.039 & 0.474 & & 2.192 & 0.031 & \multirow{2}{*}{0.465} \\
\hline & & PU & 0.787 & 0.092 & 0.687 & 8.551 & 0.000 & \\
\hline
\end{tabular}

system has a significant influence on users' behavioral intention (BI) to use the system $(\beta=0.687$, $\mathrm{p}<0.05)$ Hypothesis (H5) is supported and PU has a significant and positive impact on BI.

These findings concur with the majority of TAM research as presented by Lee et al. (2003). Their study of one-hundred and one (101) published articles showed that sixty-eight percent $(68 \%)$ of the articles found a significant relationship between PEOU and PU (hypothesis H3 of this research). Seventy-three percent (73\%) of the articles found a significant relationship between PU and BI (hypothesis $\mathrm{H} 5$ of this research). Hypotheses $\mathrm{H} 1, \mathrm{H} 2$ and $\mathrm{H} 4$ have been studied by similar TAM studies and found to be significant by a host of researchers, including Gyamfi (2016), Shroff et al (2011), and Park (2009).

\section{External Variable}

The influence of external variables on the Online Voting System (OVS) was assessed qualitatively. The twenty-sixth item of the survey instrument required respondents to affirm whether they would want to be contacted for further questions and if so, provide a contact telephone number. Thirty-three (33) respondents (39.3\%) provided contact numbers and for the sake of convenience, Short Message Service (SMS) of the telephone network operator was used to communicate with the respondents. An appreciation SMS was sent to the respondents which also carried a request for further interaction via SMS. Four (4) questions were crafted and sent in separate messages to all respondents who provided contact numbers. The response from the interesting conversations that followed have been organized, presented and interpreted as follows.

\section{What Were Some Reasons That Made You Use the OVS?}

The respondents gave reasons such as: "The reason is that is fast and good for an easy way to vote"; "Because it was new"; “...It was obligatory. And I wanted to encourage a friend"; "Actually it's easier and doesn't require much time."; "Experience"; "I used it because i was oblige to us it since i wanted my party to win - Thats all cause i personally was not for its use"; "Good Innovation, Vote At Will, Presumed It Was Credible, Great Way Of Following Global Issues, A leading Example"; "It was less time consuming, it was very fast, i could do it at anytime, and i am comfortable with online systems cause am use to it."; "Reasons were Innovation and motivation".

These motivations for using the OVS concur quite well with the external variables investigated in scholarly literature. Reading through the extracts from the SMS, the echoes of a wide variety of external 
variables, and their occurrence in scholarly literature, could be vividly identified. These include "Facilitating Conditions" (Taylor and Todd, 1995); "Voluntariness" (Venkatesh and Davis, 2000); "Trialability" (Rogers, 1983); "Social Influence" (Venkatesh and Morris, 2000); "Self-Efficacy" (Venkatesh and Speier, 2000) as well as "Personal Innovativeness" (Agarwal and Karahanna, 2000). Although these external constructs where not measured in this research, the review of literature informs the research about the existence of such constructs and the comments from respondents fit squarely into the definitions of these constructs.

\section{How Did the OVS Affect Fairness in the STUGA Elections This Year?}

Respondents found the OVS to be quite fair "I Did Not Get Any Complain Wit De System, Think Every One Was Happy As Such I Can Infer that there Was Fair-play" and more secured "I think it was a little little bit more secure" than the traditional paper - ballot box system. They also held the electoral team in high esteem "Fairness was Better because a group was accountable for transparency" but were able to point out certain operational fault with using system: "Fairness of the system was good,... though some users had ways to register others".

It is intriguing to see respondents situating the use of the OVS in the electoral context, particularly in cases where they did not agree with the outcome of the elections. "It was not fair-Because of the result", "To me what $i$ think is that, cheating online voting is not an easy thing, and if so many people don't have the opportunity to use it to vote ... ", " ... I can say it was fair to an extend, but also the fact of power rotation is important. ...". This arouses thoughts about research in the context within which technology is accepted or refuted, an area which is not popular among TAM researcher. One respondent did not feel comfortable using SMS to answer this question: "I cant answer that one through sms cause i need to explain 4 u to understand. And I cant do it through sms".

\section{What Were Some Challenges You Faced With Using the OVS?}

"Had no challenges"; "I as a person had no problem"; "I did not face any"; "Am used to online systems so...for me $i$ had no difficulties ... "; "So far it was cool, ...". These responses suggest a high level of computer literacy among the students and their confidence in using technology. The respondents were equally able to highlight critical challenges related to using the system and its responsiveness: "When you click ok for the vote there is no notification message to tell u your vote was registered of not"; " "... Slow to process - Like click to response (delay time)" as well as those related to Internet connectivity: "The Only Challenge On My Part Was Connecting To De Voting Page, Network Issues I suppose, ...", “ ... during the period in school connection was very slow.. and it took a little bit of my time, ...".

One respondent pin-pointed a problem commonly talked about in almost every election - which is getting voters registered and ensuring that they cast their votes: "For Other Both Students N Staff It Was Difficult To Get Dem Register N Vote".

\section{Any General Remarks About the OVS?}

Respondents were very supportive of the OVS and made suggestions on innovations that could be added to the system: “. .. it's something good in other to encourage youths to get used to technology ..."; "All Elections Should Employ the OVS, All Should Be Encourage To Use It, they Can Push It Forward To Display the Progress On the Screen"; "It's a good system, but if it was possible for everybody to do that using his or her phone, it would be better....". Others held that the system needs to be made more secured and its management autonomous: "Just wish they should increase the security"; " ... but there is the need for a single body or committee to take care of such things. A body not even influenced by the board of trustees nor the office of the president and even the provost, to ensure uniformity and transparency in every activity ...".

One respondent felt that the OVS “... gives room for easy cheating ... " and referring to the questions in the questionnaire, he wrote “... so maybe u should revise the questionnaires and questions 
...". Certainly, the questions in the questionnaire were not designed to measure election malpractices as the respondent is suggesting; but his concern runs deeper in TAM research. The findings from the qualitative data suggest that external variables may have a strong influence on our understanding of the context within which technology is accepted or refuted.

\section{CONCLUSION AND RECOMMENDATIONS}

This study focused on the acceptance of a locally developed software - An Online voting system (OVS), using TAM as its theoretical guide. By borrowing and adapting a survey instrument from Shroff et al. (2011), the study implicitly tests the transferability and consistency of the constructs within the said instrument. Instrument reuse is common practice among TAM researchers (Gyamfi, 2016; Olasina, 2015) and their validity is often analyzed within the research context. The analyses of construct and discriminant validity revealed that with proper adaptation, survey instruments used in a particular context can be conveniently reused in other studies and would facilitate the research process. The relationships between the various constructs were found to be supported in a similar way as in previous research. Exploration of the research context reveals tremendous support which mixing quantitative and qualitative methods can offer in informing research praxis.

\section{Implications for Research}

The process of collecting qualitative data was humbling and intriguing. Despite the fact that participants had indicated, in the questionnaires, that they would like to be contacted for further discussions, they were mostly surprised and acted unaware upon receiving the first SMS. This was probably because the first messages by SMS where sent approximately three (3) months after the questionnaires had been filled. A recommendation, for researcher who intend to use SMS for collecting qualitative data, would be to engage the participants as early as possible. This would ensure that the topic of discussion is still fresh in the minds of the participants.

The asynchronous communication, via SMS, between the researchers and the respondents was very convenient for the collection, storage and processing of the qualitative data. Respondents reacted at their comfort and the responses were processed at the convenience of the researchers. However, this approach added an extra delay in the data analysis process as the researchers had to wait for an acceptable number of response before processing them. The way respondents used and presumed the understanding of the "shorthand" and "jargons" in their SMSs was interesting and revealing. A recommendation for further research would be to investigate whether respondents have adopted such writing style, for sending messages via SMS, because it is easy to use or because it is useful.

Qualitative data conspicuously revealed information about the multitude of constructs which have been quantitatively investigated as external variable or subjunctive norms in TAM research. This echoes a central debate it the abductive / retroductive philosophy of science (Plutynski, 2011). Abduction is a third way of inference with is neither deductive nor inductive but characterized as both clever guesswork and a logical form of reason-guided inference. As Plutynski (2011) expresses, the problem of this philosophy is inherent in its historical context and researchers over the years have wondered whether abduction is an act of insight or an inference? Based on our findings, the same questions would still be true, whether participants inferred the external variable or were insightful. The role of context, therefore, remains an important frontier for even for technology acceptance researchers today.

\section{Implications for Management}

In an investigation of thirty-one (31) organizations' use of executive information systems, Averweg (2008) remarked that for a better understanding of some discrepancies in TAM research, qualitative methodologies could be applied. The findings of this study reveal that participants where focused on the context of the Online Voting System (OVS) - the Election of the Student Government President; 
rather thank the usage of the technology in the electoral process. It could be easy to over emphasis the use of the system and forget to focus on other electoral processes such as candidate registration. The implication for management, therefore, is to keep a watchful eye on context, while implementing technology-driven and or technology-dependent decisions.

In addition, when dealing with locally developed systems, management should enforce policies that support and enhance the acceptance, growth and adoption of such systems. There are numerous possible modifications to enhance and improve the system, as participants were keen to pin-point. Users easily criticized the system and the qualitative phase of the research encouraged users to be more critical. This highlighted a huge opportunity for improvement of the OVS which supports and deepens the rationale for future managerial decisions. 


\section{REFERENCES}

Afari, E. (2010). Modeling computer usage intentions of tertiary students in a developing country through the Technology Acceptance Model. International Journal of Education and Development Using Information and Communication Technology, 6(1), B1.

Agarwal, R., \& Karahanna, E. (2000). Time flies when you're having fun: Cognitive absorption and beliefs about information technology usage. Management Information Systems Quarterly, 24(4), 665-694. doi:10.2307/3250951

Ahlan, A. R., \& Ahmad, B. I. E. (2015). An overview of patient acceptance of Health Information Technology in developing countries: A review and conceptual model. International Journal of Information Systems and Project Management, 3(1), 29-48.

Al-Adwan, A., Al-Adwan, A., \& Smedley, J. (2013). Exploring students acceptance of e-learning using Technology Acceptance Model in Jordanian universities. International Journal of Education and Development Using Information and Communication Technology, 9(2), 4.

Ambak, K., Ismail, R., Abdullah, R. A., Latiff, A. A., \& Sanik, M. E. (2013). Application of technology acceptance model in predicting behavioral intention to use safety helmet reminder system. Research Journal of Applied Sciences, Engineering and Technology, 5(3), 881-888.

Averweg, U. R. (2008). Information technology acceptance in South Africa: An investigation of perceived usefulness, perceived ease of use, and actual system use constructs. The African Journal of Information Systems, $1(1), 4$.

Creswell, J. W. (2014). Educational Research: Planning, Conducting and Evaluating Quantitative and Qualitative Research (4th ed.). Pearson New.

Gelo, O., Braakmann, D., \& Benetka, G. (2008). Quantitative and qualitative research: Beyond the debate. Integrative Psychological \& Behavioral Science, 42(3), 266-290. doi:10.1007/s12124-008-9078-3 PMID: 18795385

Güllü, F., Kuusik, R., Shogenov, K., Laanpere, M., Oysal, Y., Sözcü, Ö. F., \& Parlak, Z. (2016). An Analysis and comparison of adoption of e-learning systems in higher education by lecturers at largest universities in Estonia and Turkey. Baltic Journal of Modern Computing, 4(3), 428.

Gyamfi, S. A. (2016). Identifying Ghanaian pre-service teachers' readiness for computer use: A technology acceptance model approach. International Journal of Education and Development Using Information and Communication Technology, 12(2), 105.

Hair, J. F., Anderson, R. E., Tatham, R. L., \& Black, W. C. (2003). Multivariate data analysis (5th ed.). India: Pearson Education.

Jaradat, M. I. R. M., \& Faqih, K. M. (2014). Investigating the moderating effects of gender and self-efficacy in the context of mobile payment adoption: A developing country perspective. International Journal of Business and Management, 9(11), 147. doi:10.5539/ijbm.v9n11p147

Kumar Sharma, S., Kumar Chandel, J., \& Madhumohan Govindaluri, S. (2014). Students' acceptance and satisfaction of learning through course websites. Education, Business and Society, 7(2/3), 152-166. doi:10.1108/ EBS-08-2013-0032

Ladas, C. (2008). Scrumban: Essays on Kanban Systems for Lean Software Development. Modus Cooperandi Press.

Lai, V. S., \& Li, H. (2005). Technology acceptance model for internet banking: An invariance analysis. Information \& Management, 42(2), 373-386. doi:10.1016/j.im.2004.01.007

Lee, Y., Kozar, K. A., \& Larsen, K. R. (2003). The technology acceptance model: Past, present, and future. Communications of the Association for Information Systems, 12(1), 50.

Lwasa, S., Asingwire, N., Okello, J. J., \& Kiwanuka, J. (2013). Awareness of ICT-based projects and the intensity of use of mobile phones among smallholder farmers in Uganda: The case of Mayuge and Apac districts. In Technology, Sustainability, and Rural Development in Africa (pp. 89-101). IGI Global.

Nunnally, J. (1967). Psychometric theory. New York: McGraw-Hill. 
Okuboyejo, S. R., \& Adejo, A. O. (2012). Adoption of Mobile Technology by Farmers in Southwest-Nigeria: A Cross-Sectional Study. International Journal of ICT Research and Development in Africa, 3(2), 32-44. doi:10.4018/jictrda.2012070103

Olasina, G. (2015). Factors Influencing the Use of M-Banking by Academics: Case Study Sms-Based M-Banking. The African Journal of Information Systems, 7(4), 4.

Omotayo, F., \& Dahunsi, O. (2015). Factors affecting adoption of point of sale terminals by business organizations in Nigeria. International Journal of Academic Research in Business and Social Sciences, 5(10), 115-136. doi:10.6007/IJARBSS/v5-i10/1856

Park, S. Y. (2009). An analysis of the technology acceptance model in understanding university students' behavioral intention to use e-learning. Journal of Educational Technology \& Society, 12(3), 150.

Plutynski, A. (2011). Four problems of abduction: A brief history. HOPOS: The Journal of the International Society for the History of Philosophy of Science, 1(2), 227-248.

Poppendieck, M., \& Poppendieck, T. (2003). Lean Software Development: An Agile Toolkit: An Agile Toolkit. Addison-Wesley.

Raman, A. (2011). The usage of technology among education students in University Utara Malaysia: An application of extended Technology Acceptance Model. International Journal of Education and Development Using Information and Communication Technology, 7(3), 4.

Rana, N. P., Dwivedi, Y. K., \& Williams, M. D. (2013). Evaluating alternative theoretical models for examining citizen centric adoption of e-government. Transforming Government: People. Process and Policy, 7(1), 27-49.

Rico, D. F. (2010). Lean and agile project management: for large programs and projects. Lean Enterprise Software and Systems, 37-43.

Shroff, R. H., Deneen, C. C., \& Ng, E. M. (2011). Analysis of the technology acceptance model in examining students' behavioural intention to use an e-portfolio system. Australasian Journal of Educational Technology, 27(4). doi:10.14742/ajet.940

Tan, P. J. B. (2013). Applying the UTAUT to understand factors affecting the use of English e-learning websites in Taiwan. SAGE Open, 3(4), 2158244013503837. doi:10.1177/2158244013503837

Taylor, S., \& Todd, P. A. (1995). Understanding information technology usage: A test of competing models. Information Systems Research, 6(2), 144-176. doi:10.1287/isre.6.2.144

Venkatesh, V., \& Davis, F. D. (2000). A theoretical extension of the technology acceptance model: Four longitudinal field studies. Management Science, 46(2), 186-204. doi:10.1287/mnsc.46.2.186.11926

Venkatesh, V., \& Morris, M. G. (2000). Why don’t men ever stop to ask for directions? Gender, social influence, and their role in technology acceptance and usage behavior. Management Information Systems Quarterly, 24(1), 115-139. doi:10.2307/3250981

Venkatesh, V., \& Speier, C. (2000). Creating an effective training environment for enhancing telework. International Journal of Human-Computer Studies, 52(6), 991-1005. doi:10.1006/ijhc.1999.0367

Wong, K. T. (2013). Understanding Student teachers' behavioural intention to use technology: Technology Acceptance Model (TAM) validation and testing. International Journal of Instruction, 6(1), 89-104.

Yucel, U. A., Gulbahar, Y., \& Yasemin, Y. (2013). Technology acceptance model: A review of the prior predictors. Egitim Bilimleri Fakultesi Dergisi, 46(1), 89-109. doi:10.1501/Egifak_0000001275 